\title{
Coupling mechanisms of S-Fe-P in surface sediments under the stresses of high salinity and heavy metals in coastal rivers
}

\author{
Ming Jiang ${ }^{1,2} \cdot$ Yanqing Sheng ${ }^{1}\left(\mathbb{D} \cdot\right.$ Guoqiang Zhao $^{1,2} \cdot$ Wenjing Wang ${ }^{1}$ \\ Received: 19 January 2021 / Accepted: 8 April 2021 \\ (C) The Author(s), under exclusive licence to Springer-Verlag GmbH Germany, part of Springer Nature 2021
}

\begin{abstract}
Purpose The aim of the study was to (1) investigate the distributions of sulfur ( $\mathrm{S})$, iron (Fe), and phosphorus (P) in coastal surface sediments under the stresses of high salinity and heavy metals; (2) identify potential sources and the environmental geochemical process of S-Fe mineral accumulation; and (3) elucidate the coupling mechanisms of S-Fe-P in coastal sediments under environmental stresses.

Materials and methods The distributions of reduced inorganic sulfur (RIS), inorganic $\mathrm{P}$, and reactive $\mathrm{Fe}(\mathrm{RFe}$ ) in surface sediments in two coastal rivers with heavy metals and high salinity ( $\sim 50 \mathrm{psu}$, brine drainage $)$ and in offshore areas in the Bohai Sea were investigated.

Results and discussion Pyrite sulfur (CRS) was the predominant fraction of RIS in two rivers (Jiaolai River (JL), 56\%; Jiehe River (JH), 72\%), whereas acid volatile sulfur (AVS) dominated RIS in their offshore sediments (L, 66\%; J, 45\%). RFe(II) dominated $\mathrm{RFe}$ in JH (70\%) and JL (66\%), while RFe(III) dominated the fractions in their offshore areas (53\%). Coastal surface sediments under the stresses of high salinity and heavy metals were dominated by $\mathrm{HCl}-\mathrm{P}(\mathrm{Ca}-$ bound $\mathrm{P})$ and $\mathrm{NaOH}-\mathrm{P}$ (Fe- and Albound P), respectively.

Conclusions Accumulated Fe sulfide was limited by elemental sulfur (ES) availability under high salinity, while it was limited by total organic carbon (TOC) availability when the river was heavily polluted. High salinity produced sulfide-dominated environments, which could reduce the NaOH-P and facilitate HCl-P immobilization. However, the presence of heavy metals resulted in Fe-dominated environments, which could promote metal sulfides formation and increase the NaOH-P fixation.
\end{abstract}

Keywords Inorganic sulfur $\cdot$ Phosphorus $\cdot$ Reactive iron $\cdot$ Coastal sediments

\section{Introduction}

Sulfur (S) is an important driving factor in coastal environmental evolution due to its roles as an electron acceptor, carrier, and donor (Sun et al. 2016; Latour et al. 2018; Liu et al. 2019). Sulfate reduction can significantly affect the cycling of phosphorus $(\mathrm{P})$ and iron $(\mathrm{Fe})$ in sediments and produce extensive subtoxic or anoxic zones and toxic sulfides (Wu et al. 2019; Pan et al. 2019). Especially at the sediment-water

Responsible editor: Haihan Zhang

Yanqing Sheng

yqsheng@yic.ac.cn

1 Research Center for Coastal Environment Engineering Technology of Shandong Province, Yantai Institute of Coastal Zone Research, Chinese Academy of Sciences, Yantai, China

2 University of Chinese Academy of Sciences, Beijing, China interface with frequent substance exchange, subtoxic or anoxic conditions may accelerate the pollutant or nutrient release from the sediment into the water column, thereby causing deterioration of the water quality (Pandey and Singh 2017; Jiang et al. 2020).

Anthropogenic interventions have altered the balance of salt and water in the hydrologic cycle, thereby leading to increased salinity in some coastal and inland aquatic systems (Herbert et al. 2015). This accumulation of soluble salts, which causes ions to increase above their natural levels, is known as the stress of high salinity (Cañedo-Argüelles et al. 2013). Increased salinity of the overlying water column can enhance sulfate reduction rates with high sulfate availability, which may accelerate $\mathrm{S}$ transformation and $\mathrm{P}$ immobilization by decoupling $\mathrm{S}-\mathrm{Fe}-\mathrm{P}$ interactions at the sediment-water interface (Sun et al. 2016; Wu et al. 2019). Via partial oxidation of $\mathrm{FeS}_{\mathrm{x}}$, a salinity increase may lead to the mobilization of sufficient $\mathrm{Fe}(\mathrm{II})$ at the microscale for the precipitation of $\mathrm{P}$ at the sediment-water interface (Diggelen et al. 2014). Fe-S 
complexation may increase $\mathrm{P}$ removal with salinization due to the mobilization of ions (e.g., $\mathrm{Ca}^{2+}$ and $\mathrm{Mg}^{2+}$ ) from sediment adsorption sites (Herbert et al. 2015). Neither $\mathrm{Ca}^{2+}$ nor $\mathrm{Mg}^{2+}$ can form metal sulfides, but both can combine with $\mathrm{P}$. Furthermore, increased salinity can induce an increase in $\mathrm{Ca}^{2+}$, thereby resulting in the immobilization of $\mathrm{P}$ via coprecipitation (Ca-P) (Zhao et al. 2019). Thus, the patterns of $\mathrm{S}-\mathrm{Fe}$ redox cycling are closely associated with $\mathrm{P}$ immobilization in a high-salinity environment.

Sediment pollution, especially toxic metal pollution, has been proven to be an important threat to the aquatic environment due to rapid urbanization and industrialization (Zhang et al. 2014; Souza et al. 2016). Most toxic metal pollutants (e.g., $\mathrm{Cu}, \mathrm{Zn}, \mathrm{Hg}, \mathrm{As}, \mathrm{Pb}$, and $\mathrm{Cd}$ ) are deposited in surface sediments via the formation of insoluble fractions (e.g., metal sulfides) or are adsorbed by suspended particles in water (Pandey and Singh 2017). Previous studies reported that any disturbance and/or environmental alteration at the sedimentwater interface could result in toxic metal release (Yang et al. 2011; Łukawska-Matuszewska et al. 2019). The released metal ions could generate hydroxides via hydrolysis and react with inorganic ions to form sulfide and phosphate complexes (Yi et al. 2020). Furthermore, the organic matter (OM) in polluted sediments may stimulate benthic mineralization and oxygen depletion, thereby creating an extensive anoxic environment (Liu et al. 2019; Jiang et al. 2020). Subsequently, sulfate reduction, which produced sulfides, was enhanced, and Fe-containing particles were released from $\mathrm{Fe}$ (oxy)hydroxides in the anoxic environment. Insoluble sulfide minerals (e.g., pyrite and mackinawite) were formed via the reaction of sulfides and Fe-containing particles, which are referred to as sinks for trace metals due to their affinity for metal ions (Audry et al. 2010; Oueslati et al. 2018). Additionally, sulfides can be reoxidized into elemental S (ES) by $\mathrm{Fe}(\mathrm{III})$ (oxyhydr) oxides (FeOOH) under anoxic conditions, thereby inducing chemical Fe reduction and remobilization of previously bound P (FeOOH-P) (Pan et al. 2019). After being released into porewater, the reduced Fe(II) can precipitate with the dissolved sulfide as acid volatile sulfur (AVS, FeS) and react with ES to form chromium reducible sulfur (CRS, $\mathrm{FeS}_{2}$ ) (Sheng et al. 2015). The accumulated reductive $\mathrm{S}$ and Fe minerals have minimal affinity for $\mathrm{P}$ sequestration (Thouvenot-Korppoo et al. 2012). Consequently, Fe sulfides and $\mathrm{Fe}$ oxides, via reductive dissolution, not only release the adsorbed and co-precipitated contaminants but also accelerate the release of $\mathrm{P}$ (e.g., Fe-P) from sediments (Sun et al. 2016; Pan et al. 2019).

Acid volatile sulfur and CRS are the primary fractions of RIS in coastal sediments. The ratios of AVS/CRS, the degree of pyritization (DOP), and the degree of sulfurization (DOS) can be used to distinguish whether pyrite and Fe sulfide formation is C- or Fe-limited (Sheng et al. 2015) and to identify the completeness of the reaction of $\mathrm{RFe}$ with aqueous sulfide
(Kraal et al. 2013). Previous studies have focused on S-Fe-P coupling under the influence of redox conditions (e.g., tidal inundation and eutrophication) in coastal ecosystems (Sakai et al. 2013; Sun et al. 2016), but few studies have been conducted on the mechanisms and controlling factors of S-Fe-P under the stresses of high salinity and heavy metals. Consequently, the identification of the environmental behaviors and coupling mechanisms of $\mathrm{S}, \mathrm{Fe}$, and $\mathrm{P}$ in coastal sediments is crucial to water quality management for riverestuary-offshore ecosystems.

The objectives of this study were to (1) investigate the distributions of $\mathrm{S}, \mathrm{Fe}$, and $\mathrm{P}$ in coastal surface sediments under the stresses of high salinity and heavy metals; (2) identify potential sources and the environmental geochemical process of S-Fe mineral accumulation; and (3) elucidate the coupling mechanisms of S-Fe-P in coastal sediments under environmental stresses.

\section{Material and methods}

\subsection{Study area}

The study area (Fig. 1a) includes two coastal rivers and their offshore regions. The Jiaolai River (JL, Fig. 1b) is situated on the southern bank of Laizhou Bay, Bohai Sea. The entire watershed has an area of $\sim 5479 \mathrm{~km}^{2}$, a width of $\sim 250 \mathrm{~m}$, and a total length of $130 \mathrm{~km}$. There are many salt-producing and salt-related chemical plants and salt fields along the JL due to the abundant underground brine with high salinity. Therefore, JL is a high-salinity river (up to $56 \mathrm{psu}$, Table S1) due to inputs from many salt fields on both sides (Li et al. 2016; Zhao et al. 2019). The Jiehe River (JH, Fig. 1c) is a freshwater river, which has a total watershed area of $\sim 585$ $\mathrm{km}^{2}$, a width of 70-120 m and a length of $45 \mathrm{~km}$. There are many gold mines, gold smelting plants, and vermicelli (made from bean starch, among other materials) production industries along the river. Previous studies reported the detection of high levels of heavy metals and P (up to $2797 \mathrm{mg} \mathrm{kg}^{-1}$ ) in water and sediments in JH (Zhang et al. 2014; Zhao et al. 2019). Therefore, JH is heavily polluted with $P$ and heavy metals due to waste input.

\subsection{Sample collection and handling}

A total of 33 sediment samples were collected from the study areas $(0-10 \mathrm{~cm})$. Since surface sediments are the main medium for microbial colonization and habitats in ecosystems, the surface sediments were collected using a stainless-steel grab sampler. The samples were stored in sealed plastic bags that were filled with $\mathrm{N}_{2}$ in an icebox and transported to the laboratory within $8 \mathrm{~h}$. These samples were frozen to $-20{ }^{\circ} \mathrm{C}$ in a refrigerator. The dissolved oxygen (DO), $\mathrm{pH}$, salinity, and 


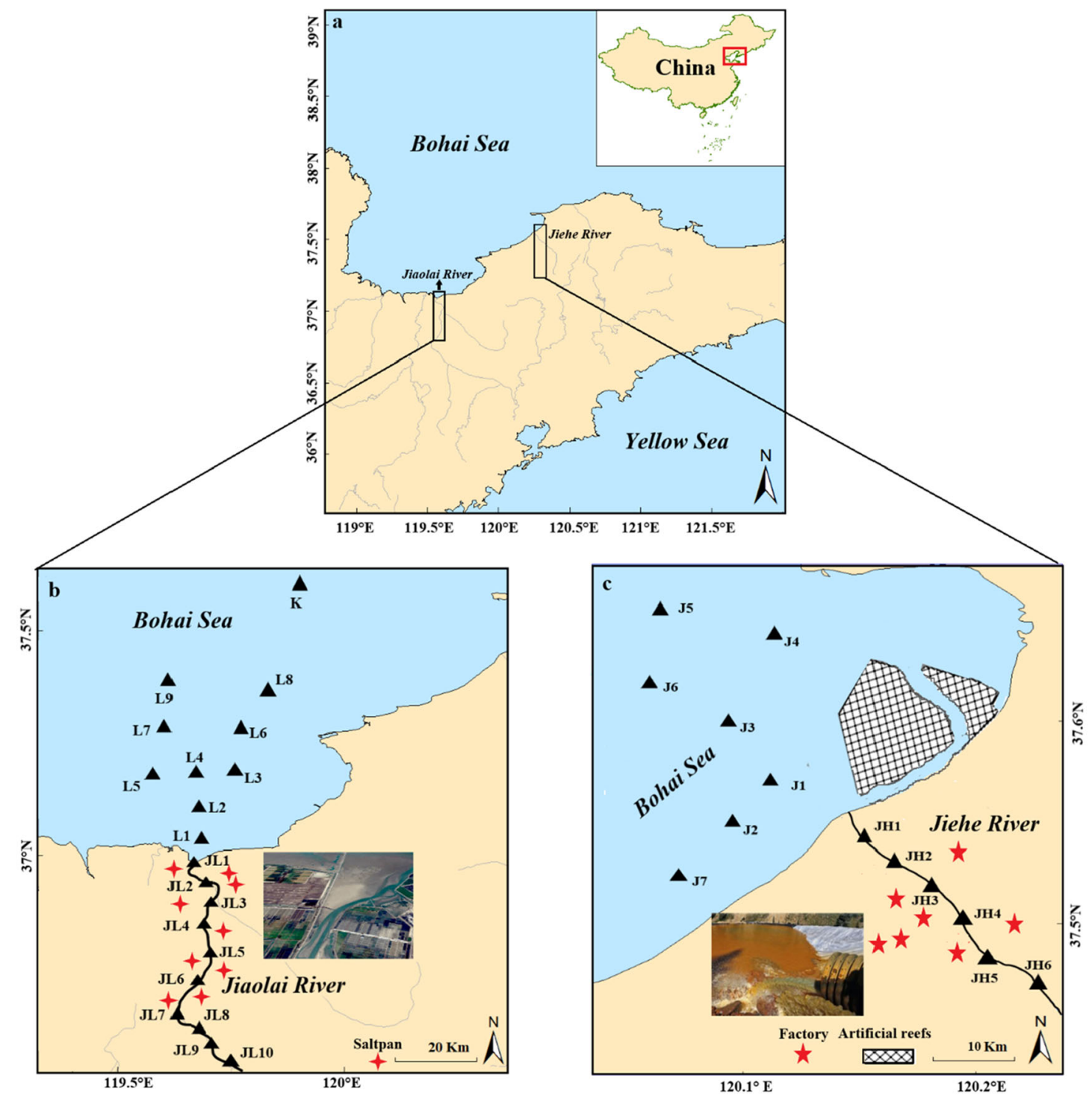

Fig. 1 Study area and locations of sampling sites (a, overall map; b, JL; and $\mathbf{c}, \mathrm{JH}$ )

oxidation-reduction potentials (ORP) of the overlying water were measured in situ using a YSI Professional Plus meter (TechTrend International Limited, USA). The supernatant of a 1: $5(\mathrm{w} / \mathrm{v})$ suspension extracted with Milli-Q water was employed for the determination of $\mathrm{pH}$ and salinity of sediments.

\subsection{Sample analysis}

\subsubsection{Total organic carbon and total nitrogen}

The vacuum freeze-dried sediment was divided into two parts using a 100 mesh sieve. One portion was treated with $\mathrm{HCl}$ overnight and washed twice using Milli-Q water to remove the carbonate. The total organic carbon (TOC) in the sediments was determined after $1 \mathrm{M} \mathrm{HCl}$ acidification (16 h, 25 ${ }^{\circ} \mathrm{C}$ ) and centrifugation $(4000 \mathrm{~g}, 15 \mathrm{~min})$. The residue was washed twice with Milli-Q water to remove carbonates and was lyophilized for TOC determination. Another portion without acid treatment was used for total nitrogen (TN) analysis. The TOC and TN in the sediment samples were analyzed using a CHNS analyzer (vario MACRO cube, Germany). The detection limit was $0.002 \%$ for TOC and $0.004 \%$ for TN.

\subsubsection{Grain size and associated metal analysis}

The OM in the sediment was removed by sodium hypochlorite $(\mathrm{NaOCl})$ prior to grain size determination (Serban et al. 2015). The sediment grain sizes were measured using a Mastersizer 2000F laser particle size analyzer (Malvern, UK). The particles were divided into three groups based on the grain size: $<4 \mu \mathrm{m}$ (clay), 4-63 $\mu \mathrm{m}$ (silt), and $>63 \mu \mathrm{m}$ (sand). Associated metals ( $\mathrm{JH}$ sediments) for $\mathrm{Cr}, \mathrm{Pb}, \mathrm{Cd}, \mathrm{Cu}$, and $\mathrm{Zn}$ were determined via inductively coupled plasma mass 
spectrometry (ICP-MS, ELAN DRC II, Perkin Elmer SCIEX, USA), and an atomic fluorescence spectrometer (Perlin Elmer, LS 55, USA) was used to analyze As and $\mathrm{Hg}$.

\subsubsection{Inorganic sulfur fractionation extraction}

The fractions of RIS mainly include AVS (fraction of sulfides that are extracted by hydrochloric acid), CRS (pyritic sulfur), and ES (a combination of oxidation products of AVS with $\mathrm{O}_{2}$, Fe oxides, and Mn oxides). RIS was conducted using a modified version of the procedure that was described by Sheng et al. (2015). AVS, CRS, and ES were separated sequentially by $6 \mathrm{M} \mathrm{HCl}$, acidic $\mathrm{Cr}(\mathrm{II})$, and $\mathrm{Cr}(\mathrm{II})$ plus $N, N$ dimethylformamide (DMF), respectively, using pure $\mathrm{N}_{2}$ as a carrier gas to purge and trap $\mathrm{H}_{2} \mathrm{~S}$ at $60 \pm 1{ }^{\circ} \mathrm{C}$. The liberated $\mathrm{H}_{2} \mathrm{~S}$ was trapped in a $0.1 \mathrm{M} \mathrm{CuCl}_{2}$ solution. The quantity of $\mathrm{H}_{2} \mathrm{~S}$ for each solid-phase RIS species was determined by titrating the $\mathrm{Cu}$ that remained in the solution with 0.1 M EDTA. Sulfide solutions $\left(\mathrm{Na}_{2} \mathrm{~S}, 0.5\right.$ and $\left.1 \mathrm{mg} \mathrm{L}^{-1}\right)$ were used in the recovery experiments. The average recovery rate was $96 \%$. The measured sulfide data were converted to the real sulfide content after correction based on the recovery rate. The precisions of the triplicate analyses were within $5 \%$ for the fractions of RIS.

\subsubsection{Reactive iron}

The reactive iron (RFe), which includes $\mathrm{RFe}(\mathrm{II})$ and $\mathrm{RFe}(\mathrm{III})$, is the fraction that can react with sulfide in sediments (Zhu et al. 2012). It was extracted by $1 \mathrm{M} \mathrm{HCl}$ to treat the wet sediments that contained RFe(II) and RFe(III), which were measured via phenanthroline colorimetry (Kraal et al. 2013). Under a protective nitrogen atmosphere, $1 \mathrm{~g}$ wet sediment was weighed in a centrifuge tube, and $50 \mathrm{~mL}$ of $1 \mathrm{M} \mathrm{HCl}$ was added. The samples were shaken for $24 \mathrm{~h}$ and centrifuged (3000g, $15 \mathrm{~min}$ ). The supernatant was filtered for RFe(II) and total RFe determination. For RFe, $1 \mathrm{~mL}$ supernatant was placed in a $150-\mathrm{mL}$ conical flask and diluted to $50 \mathrm{~mL}$ with Milli-Q water. The reduction of the entire quantity of $\mathrm{RFe}(\mathrm{III})$ to $\mathrm{RFe}(\mathrm{II})$ was ensured by adding $1 \mathrm{~mL} \mathrm{HCl}(1+3)$ and $1 \mathrm{~mL}$ $10 \%$ (wt $\%$ ) hydroxylamine hydrochloride prior to boiling. The RFe(III) content was the difference between the RFe(II) and the total RFe contents. The measurement error was less than $2 \%$ for repeated analyses.

\subsubsection{Fractionations of phosphorus}

The fractional extraction of phosphorus $(\mathrm{P})$ pools was analyzed based on the standards, measurements, and testing method (Ruban et al. 2001). Sedimentary P was divided into $\mathrm{NaOH}-\mathrm{P}$ (Fe- and Al-bound P), HCl-P (Ca-bound P), organic $\mathrm{P}$ (OP), and total P (TP). The molybdenum blue method was used to determine the P content in extracts (Murphy and Riley
1962). For the fraction analysis, $0.2 \mathrm{~g}$ sediment was calcined at $450{ }^{\circ} \mathrm{C}$ for $3 \mathrm{~h}$ to remove $\mathrm{OM}$ and extracted with $20 \mathrm{~mL}$ $3.5 \mathrm{M} \mathrm{HCl}$ for $16 \mathrm{~h}$ (Zhao et al. 2019). The TP in the extraction was determined after centrifugation $(2000 \mathrm{~g}, 15 \mathrm{~min})$; another extraction (without calcination) with $50 \mathrm{~mL} 1 \mathrm{M} \mathrm{HCl}$ was conducted for the determination of inorganic phosphorus (IP), and the OP was obtained by computing the difference between TP and IP. For the IP determination, $0.2 \mathrm{~g}$ cold-dried sediment was added to $20 \mathrm{~mL} 1 \mathrm{M} \mathrm{NaOH}$ with an extraction (16 h) and centrifuged $(2000 \mathrm{~g}, 15 \mathrm{~min})$. The $\mathrm{NaOH}-\mathrm{P}$ in the supernatant was determined, and the residue was extracted again with $20 \mathrm{~mL} 1 \mathrm{M} \mathrm{HCl}(16 \mathrm{~h})$ to obtain HCl-P.

\subsubsection{Sulfate analysis}

Sulfate in sediments was extracted according to extraction method (Yang et al. 2013) and was determined by barium chromate spectrophotometry (HJ/T 342-2007, Chinese standard). In brief, the vacuum freeze-dried sample was mixed with Milli-Q water (mass ratio 5: 1) and then was stirred for $24 \mathrm{~h}$. After centrifugation $(3000 \mathrm{~g}, 15 \mathrm{~min})$, the supernatant was added with zinc acetate and sodium hydroxide solutions to precipitate sulfide before filtered through 0.45-um membrane in an anaerobic incubator. The filtrate was diluted $\sim 15$ times for sulfate analysis using a UV-visible spectrophotometer (TU-1810, Beijing Pgeneral, China).

\subsection{Data calculation}

The DOP and DOS were calculated according to Eq. 1 and Eq. 2, respectively:

$$
\begin{aligned}
\mathrm{DOP} & =\frac{\mathrm{Fe}(\mathrm{CRS})}{\mathrm{Fe}(\mathrm{CRS})+\mathrm{Fe}(\mathrm{HCl})} \\
\mathrm{DOS} & =\frac{\mathrm{Fe}(\mathrm{AVS})+\mathrm{Fe}(\mathrm{CRS})}{\mathrm{Fe}(\mathrm{CRS})+\mathrm{Fe}(\mathrm{HCl})}
\end{aligned}
$$

where Fe (CRS) denotes pyrite-Fe, which is assumed to have the stoichiometry of $\mathrm{FeS}_{2}$; Fe (AVS) denotes sulfidebound $\mathrm{Fe}(\mathrm{II})$, which is assumed to predominantly occur as FeS (Zhu et al. 2012); and $\mathrm{Fe}(\mathrm{HCl})$ denotes the "residual" $\mathrm{RFe}$ that has not been pyritized.

\section{Results}

\subsection{Properties of water and sediments}

General parameters in overlying water and sediments are shown in Table S1. Significant characteristics were observed in JL, which had high salinity (mean 44.9 psu) and ORP (mean $644.36 \mathrm{mV}$ ), in contrast to $\mathrm{JH}$ (salinity of $1.11 \mathrm{psu}$ and ORP of $261.33 \mathrm{mV}$ ). The salinity in JL fluctuated 
between 30.3 and 56.07 psu. The $\mathrm{pH}$ in JL and JH ranged from 1.83 to 8.21 and 6.53 to 8.20 , respectively. Low $\mathrm{pH}$ values in JL presented at onshore sites from JL2 to JL8. The mean value DO in JL was $3.79 \mathrm{mg} \mathrm{L}^{-1}$, approximately onethird of that in the offshore areas (mean $6.91 \mathrm{mg} \mathrm{L}^{-1}$ ). Compared to JL, DO in $\mathrm{JH}$ was high (mean $7.13 \mathrm{mg} \mathrm{L}^{-1}$ ), which varied slightly and was close to the offshore areas.

The average sediment contents of TOC and TN in the rivers were higher than those offshore areas. The highest TOC and TN were found at JH5 (TOC, 2.30\%; TN, 0.36\%) and JL10 (TOC, $1.92 \%$; TN, $0.24 \%$ ). The total concentrations of heavy metals in $\mathrm{JH}$ showed wide variations, with $\mathrm{Cr}$ concentrations of $10.4 \sim 78.8 \mathrm{mg} \cdot \mathrm{kg}^{-1}$, As $16.8 \sim 1674 \mathrm{mg} \cdot \mathrm{kg}^{-1}, \mathrm{Cd}$ $5.2 \sim 45.2 \mathrm{mg} \mathrm{kg}^{-1}$, $\mathrm{Hg} 5.3 \sim 25.7 \mathrm{mg} \mathrm{kg}^{-1}, \mathrm{~Pb} 45.1 \sim 272 \mathrm{mg}$ $\mathrm{kg}^{-1}, \mathrm{Cu} 52.5 \sim 1257 \mathrm{mg} \mathrm{kg}^{-1}$, and $\mathrm{Zn} 101 \sim 1251 \mathrm{mg} \mathrm{kg}^{-1}$ (Table S2). According to these concentrations, As, $\mathrm{Cd}, \mathrm{Hg}$, $\mathrm{Cu}$, and $\mathrm{Zn}$ presented high levels in JH sediments, whereas $\mathrm{Cr}$ and $\mathrm{Pb}$ presented lower potential toxic pollution, which was consistent with a previous report (Song et al. 2019). The sediment grain sizes were dominated by sand in the JL (68\%) and JL coastal regions ( $82 \%$ ) (Fig. 2). However, clay dominated in $\mathrm{JH}(48 \%)$, and silt dominated in its offshore areas $(55 \%)$. Overall, the grains tended to increase in coarseness from the rivers to their offshore areas.

\subsection{Acid volatile sulfur, chromium reducible sulfur, and elemental sulfur (ES) distribution}

Sequential extraction of RIS is shown in Fig. 3. The average RIS contents of two rivers were much higher than those in their offshore areas (JH, $962 \mathrm{mg} \mathrm{kg}^{-1}>\mathrm{J}, 243 \mathrm{mg}$ $\mathrm{kg}^{-1} ; \mathrm{JL}, 869 \mathrm{mg} \mathrm{kg}^{-1}>\mathrm{L}, 248 \mathrm{mg} \mathrm{kg}^{-1}$ ), and the highest RIS was present in JH. Overall, chromium reducible sulfur (CRS) was the predominant fraction of RIS in two rivers (JL, 56\%; JH, 72\%), whereas acid volatile sulfur (AVS) dominated RIS in their offshore sediments (L, $66 \%$; J, 45\%). Relatively high concentration of RIS in $\mathrm{JH}$ (up to $1769 \mathrm{mg} \mathrm{kg}^{-1}$ ) was presented in $\mathrm{JH} 4$, JH5, and $\mathrm{JH} 1$. The AVS content of $\mathrm{JH}$ (mean $127 \mathrm{mg} \mathrm{kg}^{-1}$ ) was close to its content in offshore areas, but the CRS (696 $\mathrm{mg} \mathrm{kg}^{-1}$ ) and elemental sulfur (ES) (139 $\mathrm{mg} \mathrm{kg}^{-1}$ ) contents were $\sim 8$ - and $\sim 3$-fold higher than its content in offshore areas, respectively. RIS contents were high in the upper and middle reach of JL (JL5 to JL9, except JL10) but was low downstream (JL1 to JL4), which showed a similar pattern as the distribution of high salinity. The mean AVS (117 $\mathrm{mg} \mathrm{kg}^{-1}$ ), CRS (662 $\mathrm{mg} \mathrm{kg}^{-1}$ ), and ES $\left(91 \mathrm{mg} \mathrm{kg}{ }^{-1}\right.$ ) concentrations in JL were approximately $\sim 1-, \sim 7-$, and $\sim 3$-fold higher than that in offshore sediments, respectively.

\subsection{Distribution of reactive iron}

Figure 4 shows the profiles of $\mathrm{RFe}$, which represents the sum of the extracted RFe(II) and RFe(III) from sediments. The average TRFe in rivers was $\sim 2$ times higher than that in offshore areas. In JH, the mean values of $\mathrm{RFe}(\mathrm{II})$ and $\mathrm{RFe}(\mathrm{III})$ were $2658 \mathrm{mg} \mathrm{kg}^{-1}$ and $1073 \mathrm{mg} \mathrm{kg}^{-1}$, respectively, which exceeded those in the offshore areas $\left(\sim 920 \mathrm{mg} \mathrm{kg}^{-1}\right)$. In JL, the average RFe(II) was $\sim 2$ times higher than in its offshore areas, whereas the reverse was true for $\mathrm{RFe}$ (III) (1 2 times). Furthermore, RFe(II)
Fig. 2 Grain sizes of sediments in rivers and their offshore areas

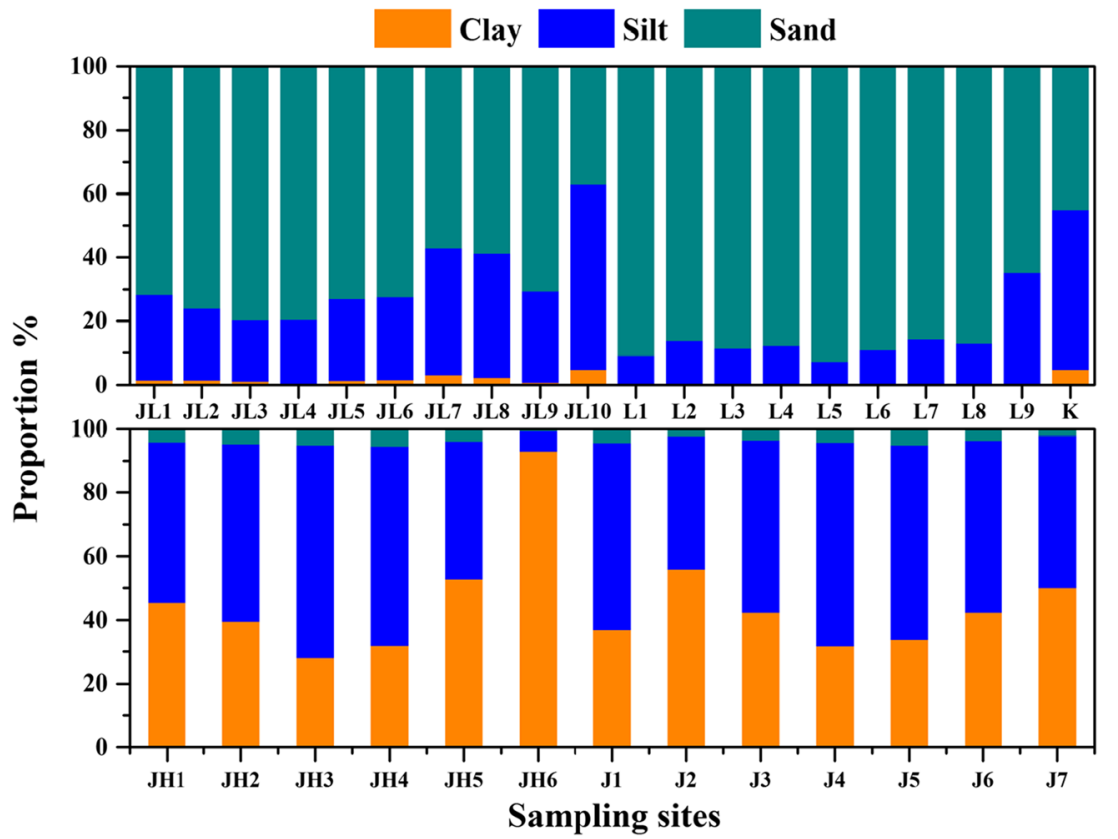


Fig. 3 Distributions of reduced inorganic sulfur (RIS) in sediments in rivers and offshore areas

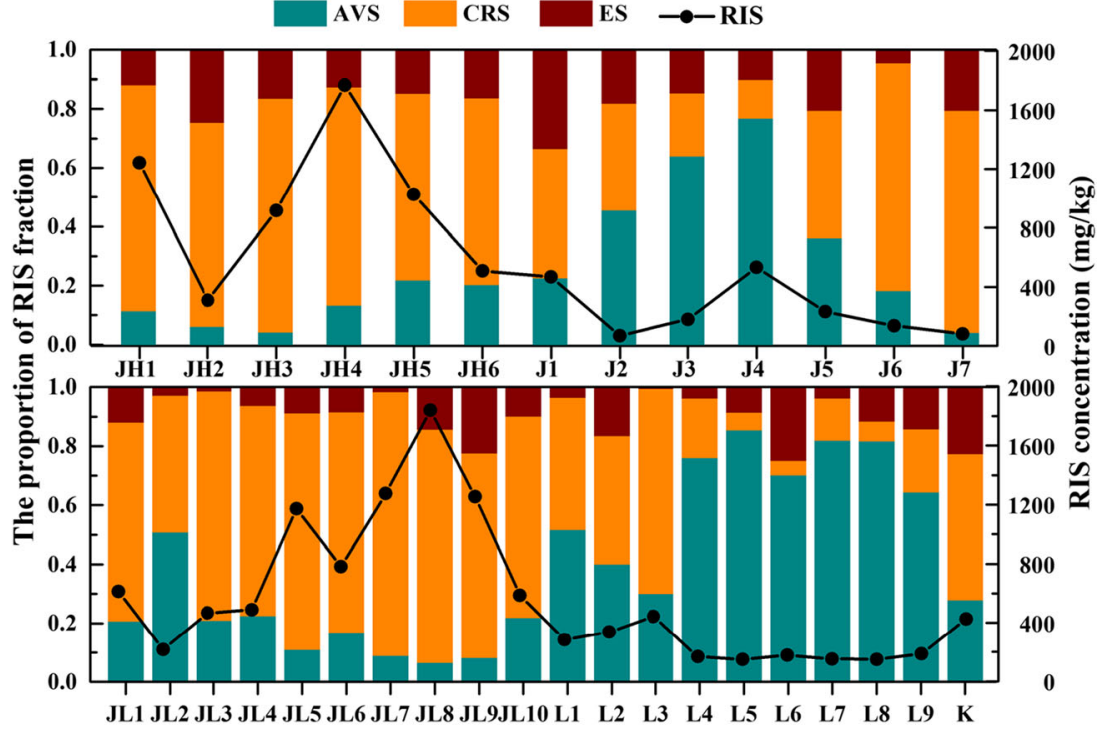

Sampling sites dominated total $\mathrm{RFe}$ in $\mathrm{JH}(70 \%)$ and $\mathrm{JL}(66 \%)$, while $\mathrm{RFe}(\mathrm{III})$ dominated the fractions in their offshore areas $(53 \%)$.

\subsection{Sulfate distribution}

The distribution of sulfate in the sediments is shown in Fig. 5. The contents in $\mathrm{JH}$ (121 to $2077 \mathrm{mg} \mathrm{kg}^{-1}$ ) and JL (446 to $6980 \mathrm{mg} \mathrm{kg}^{-1}$ ) were 1-3 times higher than those in their offshore areas. In JL, the average sulfate concentration (1888 mg $\mathrm{kg}^{-1}$ ) in the river substantially exceeded that in the offshore regions (1296 $\mathrm{mg} \mathrm{kg}^{-1}$, Dang et al. 2013), which was related to the residual brine discharge from the adjacent salt plants. The mean sulfate in $\mathrm{JH}\left(891 \mathrm{mg} \mathrm{kg}^{-1}\right)$ was close to that in normal sediments (Zhang et al. 2014).

Fig. 4 Distributions of Fe(II) and $\mathrm{Fe}(\mathrm{III})$ in sediments in rivers and their offshore areas

\subsection{Distribution of the phosphorus fractions}

The distribution of the $\mathrm{P}$ fractions in sediments is illustrated in Fig. S1. In the study areas, IP was the dominant $\mathrm{P}$ species, which included HCl-P and NaOH-P. HCl-P accounted for 63 to $90 \%$ of the TP (mean $463.2 \mathrm{mg} \mathrm{kg}^{-1}$ ) in JL (high salinity), which was followed by NaOH-P (5 to $17 \%$ ). OP showed the lowest proportion (3 to 24\%). The TP (mean $362 \mathrm{mg} \mathrm{kg}^{-1}$ ) decreased from the rivers to the offshore areas. In JL and its offshore areas, TP varied substantially. The highest TP $\left(583.5 \mathrm{mg} \mathrm{kg}^{-1}\right)$ was observed in JL8 ( HCl-P constituted $67 \%$ of TP, whereas OP constituted $21 \%$ of TP). In JH, the values for TP (mean $1785.3 \mathrm{mg} \mathrm{kg}^{-1}$ ), HCl-P (23 to $51 \%$ ), $\mathrm{NaOH}-\mathrm{P}$ (34 to $68 \%$ ), and OP (7 to $15 \%$ ) exceeded the corresponding values for JL. NaOH-P dominated TP, namely, it

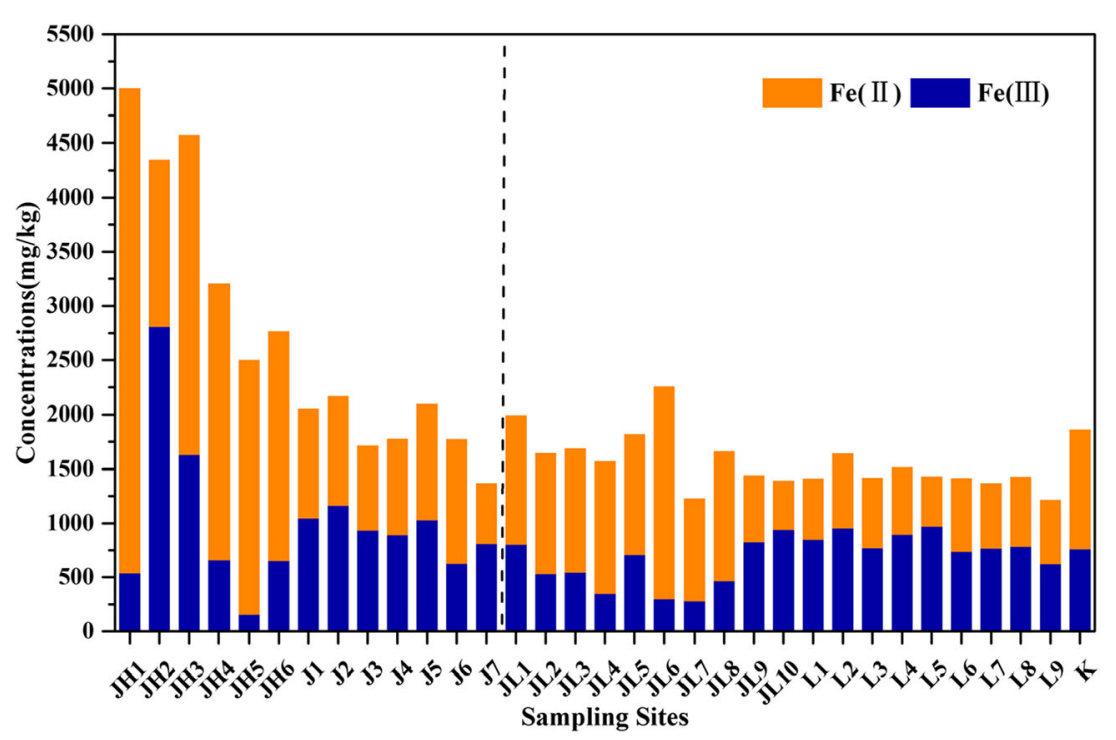


Fig. 5 Distributions of sulfate in sediments in rivers and their offshore areas

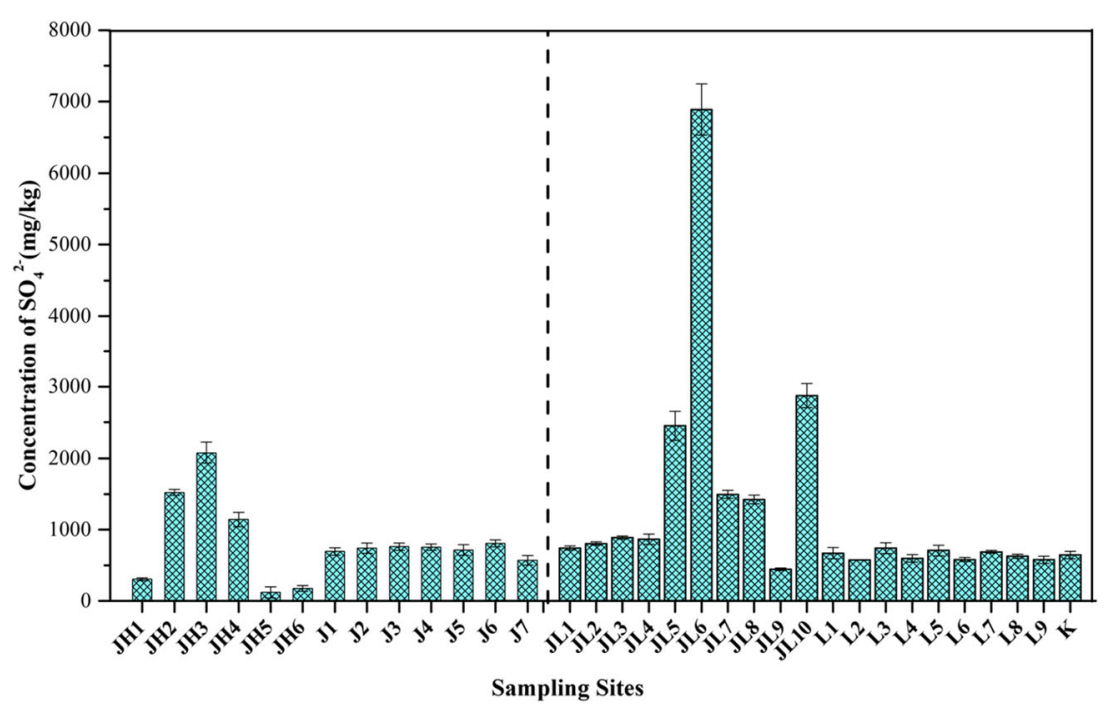

exceeded $1200 \mathrm{mg} \mathrm{kg}^{-1}$ in JH1, JH4, and JH5. The highest TP (2797 $\mathrm{mg} \mathrm{kg}^{-1}$ ) was detected in JH5 with 64\% $\mathrm{HCl}-\mathrm{P}$ and $13 \%$ $\mathrm{OP}$, and it remained in a narrow range (with an average value of $362 \mathrm{mg} \mathrm{kg}^{-1}$ ) in offshore areas.

\section{Discussion}

\subsection{Sediment characteristics and the depositional organic matter source}

Typically, the grains in riverine sediments are coarser than those in marine sediments (Zhuang and Gao 2013). However, in this study, most JL and JH sediments were finer than those in their offshore areas. The components of most marine sediments became finer from the offshore area to the outer sea. Salinity is known to increase the cohesion of clay minerals and, thus, the flocculation of fine-grained sediments in suspension (Serban et al. 2015). This was supported by the positive correlation between sediment salinity and fine particles (clay and silt) in JL $\left(R^{2}=0.78, p<0.01\right.$; Fig. S2 a). In JH, numerous metal particles that have been released from mining operations have been deposited in the bottom and bank sediments along stream channels (Zhang et al. 2014; Song et al. 2019). Among the investigated metals, $\mathrm{Cr}, \mathrm{Pb}, \mathrm{Zn}$, and $\mathrm{Cu}$ showed significant positive correlations with clay (Table S3); hence, these metals more strongly bind with finer particles than larger sand particles. Such environments provided suitable conditions for the resuspension of fine sediments near estuaries and, subsequently, drove them to offshore areas (Serban et al. 2015; Enya et al. 2020). Under the joint effects of the tidal and residual currents and the anti-clockwise circulation of the offshore areas, the fine surface sediments near the estuaries were resuspended and driven to the outer sea (Gao et al. 2015). Therefore, the coarse particles with weak adsorption forces remained in offshore areas.

The $\mathrm{C} / \mathrm{N}$ ratio can be used to discriminate terrestrial and marine sources of OM in estuarine sediments (Leng and Lewis 2017). Phytoplankton typically has a $\mathrm{C} / \mathrm{N}$ ratio that is between 4 and 10 due to its low-cellulose and high-protein composition, whereas land plants have $\mathrm{C} / \mathrm{N}$ ratios that exceed 15 due to the high-cellulose and high-lignin compositions of vascular terrigenous plants (Yang et al. 2011). In this study, large $\mathrm{C} / \mathrm{N}$ ratios ( $>15$ ) were observed at sites JH6 and JL5 to JL7, and at partial sites near the river mouths (Table S4). This result was larger than expected according to the marine phytoplankton composition $(\mathrm{C} / \mathrm{N} \sim 6)$; hence, external inputs and internal phytoplankton significantly impacted the study areas.

\subsection{Sulfur-iron sedimentation under high salinity and heavy pollution}

The molar ratio of AVS to RFe represents the potential reactivity between the sulfides and trace metals (Cooper and Morse 1998). If AVS constitutes more than $20 \%$ of RFe, sufficient sulfide will be available for the effective trapping of heavy metals. In this study, the AVS/RFe ratios in the rivers ranged from 0.05 to $0.53(\mathrm{JL})$ and from 0.01 to $0.15(\mathrm{JH})$ (Table S4). These results demonstrated that AVS formation may result in the shifting and release of trace metals at the $\mathrm{JH}$ sediment-water interface. Instead, the sulfides in JL sediments could efficiently trap and inhibit the rerelease of these metals to the overlying water. Therefore, trace metals could form strong ligand complexes, coprecipitate with Fe sulfides, or be adsorbed to the surfaces of AVS and CRS (Audry et al. 2010; Oueslati et al. 2018). Due to oxidation and conversion into CRS, the AVS content near the sediment-water interface was low (Fig. 3). Moreover, the continued dissolution of metastable $\mathrm{Fe}$ oxyhydroxides and the release of high heavy 
metals (adsorbed/bound to OM) resulted in an Fe-dominated system in JH (Cooper and Morse 1998). Such processes enhanced metal-ligand formation while increasing the net anion exchange between AVS and trace metals, thereby promoting the coprecipitation of trace metal sulfides with AVS (Oueslati et al. 2018; Yi et al. 2020). However, continued sulfate reduction will ultimately exhaust the finite supply of metastable Fe oxyhydroxides due to an insufficient supply of oxidants under high salinity (Henneke et al. 1997; Jordan et al. 2008). The processes increased the RFe proportion that was associated with the AVS, thereby resulting in a sulfide-dominated system in JL (Pandey and Singh 2017). Such processes inhibited metal-ligand formation while favoring the formation of metal sulfides, thereby promoting CRS accumulation to sequester trace metals within CRS via the reaction of FeS with aqueous polysulfide or $\mathrm{H}_{2} \mathrm{~S}$.

DOP and DOS provide guidance on the limiting formation of CRS and Fe sulfides, and the AVS/CRS ratio is used to ascertain the conversion of AVS to CRS (Raiswell and Berner 1985). In this study (Table S4), the DOP and DOS values in JL ( 0.38 and 0.48 , respectively) and $\mathrm{JH}(0.25$ and 0.30 , respectively) exceeded those in their offshore areas (L, 0.09 and 0.20 , respectively; J, 0.08 and 0.17 , respectively); hence, the conversion of RFe to CRS effectively occurred in JH and JL, and pyritization and sulfurization were not limited by the availability of RFe (Zhu et al. 2012; Jiang et al. 2020). Additionally, the mean AVS/CRS ratios in JL and JH were 0.34 and 0.19 , respectively; thus, efficient conversion of AVS to CRS could occur in JL and JH. The result was in agreement with a previous study, in which effective conversion of AVS to CRS occurred in sediments (Oueslati et al. 2018).

Acid volatile sulfur can be converted to CRS in the sediment by following polysulfide and $\mathrm{H}_{2} \mathrm{~S}$ pathways (Eqs. 3 and 4) (Raiswell and Berner 1985). A previous study showed that Eq. 4 predominated when the $\mathrm{pH}$ was approximately 7 in sediments (Oueslati et al. 2018). According to the $\mathrm{pH}$ values (5.4, Table S4), the formation of CRS in JL might be attributed to Eq. 3 since the sulfate-reducing reaction at lower $\mathrm{pH}$ was less efficient due to the accumulation of hydrogen ions, which inhibited the formation of polysulfide (Eqs. 5 and 6) (Yang et al. 2020). Temporary aerobic conditions followed the inflow of highly saline surface water from the salt fields on both sides, thereby enhancing the oxidation of $\mathrm{RFe}$ and $\mathrm{H}_{2} \mathrm{~S}$ (Latour et al. 2018; Zhao et al. 2019). This resulted in the formation of $\mathrm{Fe}(\mathrm{III})$-oxyhydroxides (e.g., FeOOH) and $\mathrm{ES}$ (Sun et al. 2016). This increased the amount of RFe that was available for the reaction with $\mathrm{H}_{2} \mathrm{~S}$ at lower $\mathrm{pH}$ in high-salinity sediments, thereby resulting in RFe being precipitated as CRS (Eq. 7) (Lukawska-Matuszewska et al. 2019). This may be explained by the negative relationship between the $\mathrm{pH}$ and CRS $\left(R^{2}=0.54, p<0.01\right.$; Fig. S2 b), and CRS was significantly correlated with salinity $\left(R^{2}=0.66, p<0.01\right.$; Fig. S2 c) in JL. Additionally, salinity or the amount of sulfate present in
JL had a stronger effect on $\mathrm{H}_{2} \mathrm{~S}$ production. Previous reports have suggested that that $\mathrm{H}_{2} \mathrm{~S}$ concentration and production rates increase with sulfate at high-salinity water (Sakai et al. 2013; Letelier-Gordo et al. 2020). This implied that the sulfide-rich sediments enabled excess sulfide to diffuse into surface sediments or above the sediment-water interface via the dissimilatory reduction of sulfate (Henneke et al. 1997; Sakai et al. 2013). Studies have shown that Fe sulfurization could be governed by reductive conditions in surface sediments even if the overlying water is oxic (Oueslati et al. 2018; Jiang et al. 2020). Thus, the oxidation of sulfide might be associated with the formation of ES, which would enhance the CRS accumulation in surface sediments under high salinity. A significant correlation between ES and CRS $\left(R^{2}=0.69\right.$, $p<0.01$; Fig. S2d) was identified, which clearly demonstrated that ES was a dominant limiting factor for the AVS conversion to CRS under high salinity in JL.

However, for Fe-rich sediments that were deposited under mining-contaminated environments (oxygenated bottom water), CRS was significantly correlated with TOC $\left(R^{2}=0.47, p\right.$ $<0.01$; Fig. S2 e) and ES ( $R^{2}=0.77, p<0.01$; Fig. S2 f) in JH. This might suggest that the availabilities of TOC and ES played important roles in controlling CRS formation in $\mathrm{JH}$ (Zhu et al. 2012; Yang et al. 2020). Such relationships could also be attributed to the transformations of AVS and ES, which accelerate pyritization and increase RFe availability (Oueslati et al. 2018; Łukawska-Matuszewska et al. 2019). Fe-dominated sediments demonstrated a source-sink behavior with respect to sulfide minerals and associated trace metals, and there was less aqueous sulfide available for the potential inhibition of metal-ligand formation (Cooper and Morse 1998). The supply of RFe(II) might transiently exceed the supply of sulfide in Fe-rich sediments. Thus, RFe(II) could react quickly with sulfide to sequester it as AVS, thereby enabling bioturbation in surface sediments (Oueslati et al. 2018; Wu et al. 2019). This resulted in a renewed supply of oxygen and sulfate from the overlying water, thereby increasing the formation of CRS (Eqs. 3 and 8) and the release of heavy metals (via aerobic decomposition of organic compounds) in JH. Consequently, a significant positive correlation between $\mathrm{RFe}(\mathrm{II})$ and CRS was identified $\left(R^{2}=0.69, p<0.01\right.$; Fig. S2 g). Such environments cause an imbalance between the inflow of oxygen and the consumption of oxygen via mineralization processes (Lukawska-Matuszewska et al. 2019; Yi et al. 2020). Overall, Fe-dominated sediments lowered the availability of TOC, which, in turn, became the dominant limiting factor for CRS formation in heavily polluted environments.

$$
\begin{aligned}
& \mathrm{FeS}+\mathrm{S}^{0} \rightarrow \mathrm{FeS}_{2} \\
& \mathrm{FeS}+\mathrm{H}_{2} \mathrm{~S} \rightarrow \mathrm{FeS}_{2}+\mathrm{H}_{2} \\
& \mathrm{SO}_{4}{ }^{2-}+\text { lactate } \rightarrow \text { acetate }+\mathrm{HS}^{-}+\mathrm{H}^{+}+\mathrm{HCO}_{3}{ }^{-}
\end{aligned}
$$




$$
\begin{aligned}
& \mathrm{HS}^{-}+\mathrm{Fe}^{2+} \rightarrow \mathrm{FeS}_{\mathrm{x}}+\mathrm{H}^{+} \\
& \mathrm{FeOOH}+\mathrm{H}_{2} \mathrm{~S}+\mathrm{H}^{+} \rightarrow \mathrm{FeS}_{2}+4 \mathrm{H}_{2} \mathrm{O}+\mathrm{Fe}^{2+} \\
& 2 \mathrm{FeS}+1 / 2 \mathrm{H}_{2} \mathrm{O}+3 / 4 \mathrm{O}_{2} \rightarrow 1 / 8 \mathrm{~S}^{0}+\mathrm{FeOOH}
\end{aligned}
$$

\subsection{Coupling mechanisms of S-Fe-P}

The cycling process of $\mathrm{S}, \mathrm{Fe}$, and $\mathrm{P}$ in surface sediments under the stresses of high salinity and heavy metals is illustrated in a schematic diagram (Fig. 6). The mobilization of sedimentary $\mathrm{P}$ was typically affected by the geochemical reaction of $\mathrm{S}$ and $\mathrm{Fe}$ under redox conditions. Significant correlations were observed between NaOH-P and $\mathrm{Fe}(\mathrm{II})$ in $\mathrm{JH}\left(R^{2}=0.53, p<0.01\right.$; Fig. $\left.\mathrm{S} 2 \mathrm{~h}\right)$; similar correlations were also observed in $\mathrm{JL}\left(R^{2}=0.37, p<\right.$ 0.01 ; Fig. S2 i). These phenomena clearly demonstrate that $\mathrm{Fe}$ redox controlled $\mathrm{P}$ transformation in the sediments. However, the high NaOH-P and low HCl-P contents in JH (Fig. S1) may indicate that P mainly combined with metal oxides or hydroxides (Thouvenot-Korppoo et al. 2012; Zhao et al. 2019). Additionally, NaOH-P was positively associated with CRS $\left(R^{2}=0.66, p<\right.$ 0.01 ; Fig. S2 j) and TOC $\left(R^{2}=0.91, p<0.01\right.$; Fig. S2 $\mathrm{k}$ ) in $\mathrm{JH}$. Hence, the fixation of $\mathrm{Fe}-\mathrm{P}$ was directly affected by $\mathrm{FeS}_{\mathrm{x}}$ formation via $\mathrm{OM}$ decomposition because the transformation of $\mathrm{P}$ was mainly caused by the oxidation of $\mathrm{Fe}$ (III) in sediments ( $\mathrm{Li}$ et al. 2013). The supply of $\mathrm{FeOOH}$ might transiently exceed the supply of sulfide in Fe-rich sediments (Pan et al. 2019). Moreover, the organic colloids that formed from the aerobic breakdown of $\mathrm{OM}$ were covered on an inorganic solid surface (e.g., clay minerals, alumina, $\mathrm{Fe}$ oxide and calcium carbonate) (Leng and Lewis 2017). Thus, there was sufficient formation of $\mathrm{FeOOH}$ to bound $\mathrm{P}$ fixation, thereby resulting in the increase in the NaOH-P in the aerobic layer of JH (Fig. S1).

However, heavy metal pollution with larger inputs of labile carbon would require higher sedimentary oxygen demand (Sakai et al. 2013), thereby decreasing the redox potential to enhance sulfate reduction and heavy metal (adsorbed/bound to OM) release in JH. Accumulated sulfide could reductively dissolve sediment Fe oxides into reduced $\mathrm{RFe}(\mathrm{II})$, which was sequestered as $\mathrm{FeS}_{\mathrm{x}}$ in sediments (Thouvenot-Korppoo et al. 2012). Published studies have demonstrated that heavy metals bound sulfides could significantly influence above redox reactions by complexation of sulfides (Oueslati et al. 2018; Enya et al. 2020). For an instance, the direct formation of sulfide metals and/or the displacement between RFe(II) in AVS and divalent metals to form more insoluble metal sulfides. This could also explain why the RFe(II) was generally high in JH (Fig. 4). Additionally, there were two pathways for the released phosphate from Fe-bound $\mathrm{P}$ under anoxic conditions (Slomp et al. 2013). Part of this phosphate diffused upwards toward the oxidized surface layer, where it was again trapped in the surface sediment as Fe-bound P. A major proportion of the phosphate diffused downwards, however, where it met upward diffusing $\mathrm{RFe}(\mathrm{II})$ and precipitated as vivianite (Fe(II)P). Therefore, heavy metal pollution of sediments promoted the fixation of $\mathrm{P}$ while increasing $\mathrm{NaOH}-\mathrm{P}$ in JH (Fig. S1). Both the negative correlation between most heavy metals and AVS (Table S3) and the significant positive correlation between the RFe(II) and NaOH-P $\left(R^{2}=0.53, p<0.01\right.$; Fig. S2 h) in JH confirmed the above hypothesis. Overall, the heavy metal pollution resulted in $\mathrm{Fe}$-dominated environments, which could promote metal sulfides formation and increase the NaOH-P fixation.

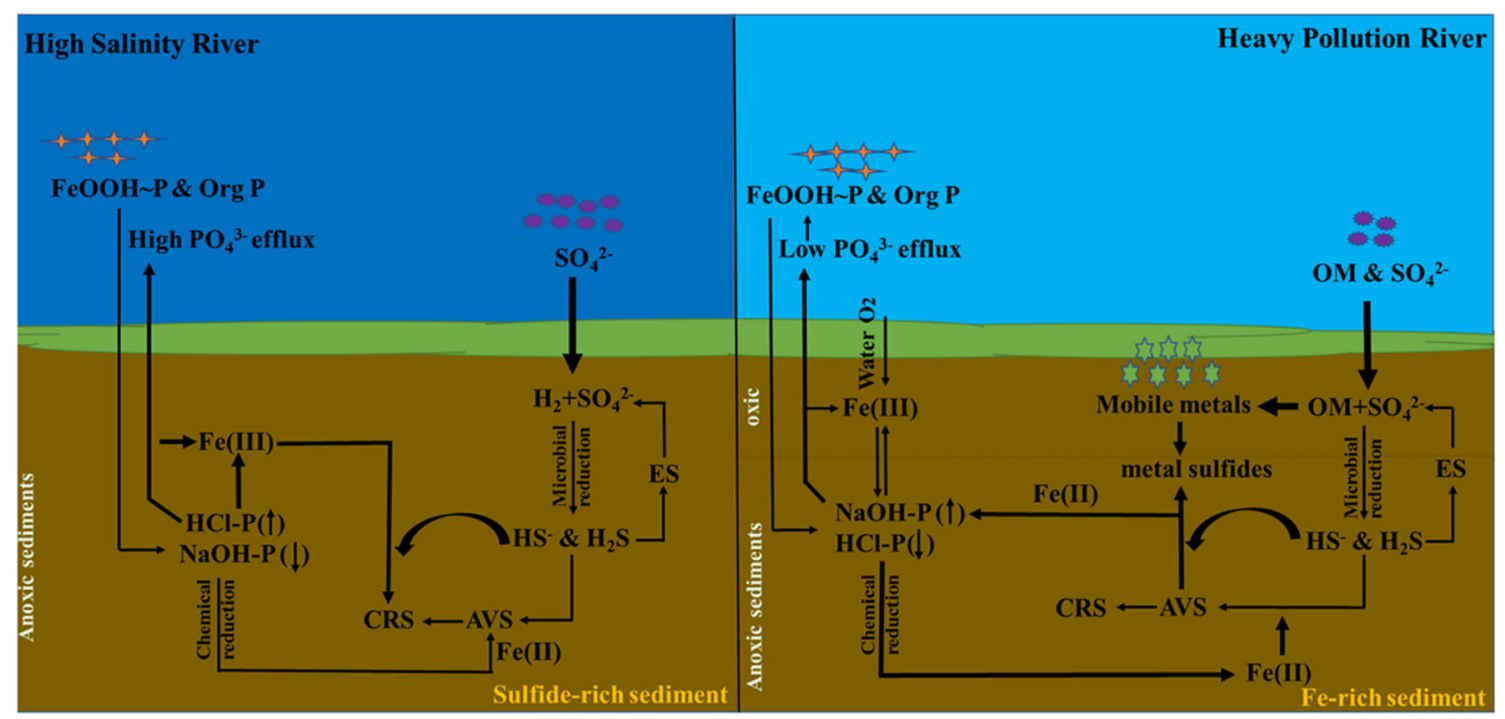

Fig. 6 Schematic overview of S, Fe, and P cycles in surface sediments in coastal rivers 
However, the sediments in JL were dominated by $\mathrm{HCl}-$ $\mathrm{P}$; thus, most $\mathrm{P}$ was associated with poorly soluble $\mathrm{Ca}$ phosphates (hydroxyapatite and fluorapatite) ( $\mathrm{Li}$ et al. 2013). Previous study showed that high salinity leads to increased $\mathrm{Ca}^{2+}$ concentrations, which caused the immobilization of $\mathrm{P}$ by co-precipitation with $\mathrm{Ca}^{2+}$ and calcium sulfate in JL (Zhao et al. 2019). Thus, the HCl-P in JL was deemed a stable fraction of inorganic $\mathrm{P}$ in sediments. It could be utilized by organisms with difficulty or released into the overlying water (Diggelen et al. 2014). A strong negative correlation was observed between the salinity and the $\mathrm{pH}\left(R^{2}=0.73, p<0.01\right.$; Fig. S2 1$)$; hence, the discharged wastewater from the salt plants contained abundant hydrogen and oxidizing ions, which could increase the ORP and sulfate. There were relatively high ORP and low pH at sites from JL 2 to JL7 (Table S1). Increased sulfate loadings to aquatic ecosystems have been shown to promote $\mathrm{P}$ release to overlying water (Pan et al. 2019; Guan et al. 2020). Salinity effects on P release from sediments could be mediated by $\mathrm{pH}$ due to an increase in alkalinity associated with sulfate reduction in saline water (Jordan et al. 2008). Previous studies have reported that high sulfate concentrations could compete with phosphate for anion adsorption sites (CañedoArgüelles et al. 2013). Sulfide, produced through sulfate reduction, would react with oxygen and interfere with the oxidation of $\mathrm{FeS}_{\mathrm{x}}$ under acidic conditions (Eq. 7), or again immobilize RFe(II) (Kraal et al. 2013). As a result, accumulated sulfide was precipitated as $\mathrm{FeS}_{\mathrm{x}}$ in sediments, which, in turn, reduced the availability of Fe(III) compounds for binding $\mathrm{P}$ (Thouvenot-Korppoo et al. 2012). This could also explain why the active $\mathrm{NaOH}-\mathrm{P}$ fraction was generally low in JL (Fig.S1). Similar studies had been conducted, and the results agreed well with the effect of salinity on Fe-bound P (Jordan et al. 2008). Because intense sulfate reduction at high salinity could remobilize $\mathrm{Fe}(\mathrm{III})$-bound $\mathrm{P}$ by sulfate-reducing bacteria and chemical Fe reduction (Pan et al. 2019), this provided the competitive advantage of reductant $\mathrm{S}$ for $\mathrm{Fe}$ ions with phosphate under acidic conditions (Eq. 9) (Guan et al. 2020).

$$
\begin{aligned}
& 2 \mathrm{FeOOH}^{-} \mathrm{PO}_{4}+6 \mathrm{CH}_{2} \mathrm{O}+3 \mathrm{SO}_{4}{ }^{2-} \rightarrow 6 \mathrm{HCO}_{3}{ }^{-}+\mathrm{FeS} \\
& +\mathrm{FeS}_{2}+4 \mathrm{H}_{2} \mathrm{O}+2 \mathrm{PO}_{4}{ }^{3-}
\end{aligned}
$$

The strong relationship between sulfate and $\mathrm{RFe}(\mathrm{II})$ supported our assumption $\left(R^{2}=0.42, p<0.01\right.$; Fig. $\left.\mathrm{S} 2 \mathrm{~m}\right)$. This was in accordance with the increase of solid-phase $\mathrm{S}$ pool in JL (Fig. 3). Therefore, high-salinity environments with high sulfate promoted RIS accumulation, leading to the release of Fe-bound P in JL. Moreover, in our study, RIS was significantly correlated with salinity $\left(R^{2}=0.70, p<0.01\right.$; Fig. S2 n) and NaOH-P $\left(R^{2}=0.60, p<0.01\right.$; Fig. S2 o) in JL. Overall, the occurrence of sulfate reduction induced $\mathrm{P}$ remobilization under high salinity.

\section{Conclusions}

The cycling of $\mathrm{S}, \mathrm{Fe}$, and $\mathrm{P}$ in high-salinity and heavily polluted rivers was investigated. The production or accumulation of RIS was regulated by $\mathrm{RFe}$ and $\mathrm{OM}$, which significantly altered the immobilization and release of $\mathrm{P}$ from sediments. The key findings of this study are summarized as follows: (1) Accumulated Fe sulfide was limited by ES availability under high salinity, while it was limited by TOC availability when the river was heavily polluted. (2) The interaction of S-Fe under high-salinity stress produced sulfide-dominated environments, which could reduce $\mathrm{NaOH}-\mathrm{P}$ (Fe-bound $\mathrm{P}$ ) and facilitate $\mathrm{HCl}-\mathrm{P}$ (Ca-bound $\mathrm{P}$ ) immobilization. The presence of heavy metals resulted in Fe-dominated environments, which could promote metal sulfides formation and increase the $\mathrm{NaOH}-\mathrm{P}$ fixation.

Supplementary Information The online version contains supplementary material available at https://doi.org/10.1007/s11368-021-02948-5.

Funding This research was conducted with financial support from the Strategic Priority Research Program of the Chinese Academy of Sciences (Grant No: XDA23050203) and the Key Project of Shandong Provincial Natural Science Foundation (Grant No: ZR2020KE048). Additional support was from the Key Project of Research and Development Plan of Yantai (Grant No: 2018ZHGY083) and the Key Research and Development Program of Shandong Province (Grant No. 2019GSF109002).

\section{References}

Audry S, Grosbois C, Bril H et al (2010) Post-depositional redistribution of trace metals in reservoir sediments of a mining/smelting-impacted watershed (the Lot River, SW France). Appl Geochem 25(6):778794. https://doi.org/10.1016/j.apgeochem.2010.02.009

Cañedo-Argüelles M, Kefford BJ, Piscart C et al (2013) Salinisation of rivers: an urgent ecological issue. Environ Pollut 173:157-167. https://doi.org/10.1016/J.ENVPOL.2012.10.011

Cooper DC, Morse JW (1998) Biogeochemical controls on trace metal cycling in anoxic marine sediments. Environ Sci Technol 32(3): 327-330. https://doi.org/10.1021/es970387e

Dang H, Zhou H, Zhang Z et al (2013) Molecular detection of candidatus scalindua pacifica and environmental responses of sediment anammox bacterial community in the Bohai Sea, China. PLoS One 8(4):e61330. https://doi.org/10.1371/journal.pone.0061330

Diggelen JMHV, Lamers LPM, Dijk GV et al (2014) New insights into phosphorus mobilisation from sulphur-rich sediments: timedependent effects of salinisation. PLoS One 9(11). https://doi.org/ 10.1371/JOURNAL.PONE.0111106

Enya O, Heaney N, Iniama G, Lin C (2020) Effects of heavy metals on organic matter decomposition in inundated soils: microcosm 
experiment and field examination. Sci Total Environ 724:138223. https://doi.org/10.1016/j.scitotenv.2020.138223

Gao X, Zhuang W, Chen C-TA, Zhang Y (2015) Sediment quality of the SW coastal Laizhou Bay, Bohai Sea, China: a comprehensive assessment based on the analysis of heavy metals. PLoS One 10(3). https://doi.org/10.1371/JOURNAL.PONE.0122190

Guan L, Xia Z, Jin L, Xu Y, He Y (2020) Influence of sulfate reduction on fraction and regeneration of phosphorus at sediment-water interface of urban malodorous river. Environ Sci Pollut Res:1-9. https://doi. org/10.1007/S11356-020-11187-Z

Henneke E, Luther GW, Lange GJD, Hoefs J (1997) Sulphur speciation in anoxic hypersaline sediments from the eastern Mediterranean Sea. Geochim Cosmochim Acta 61(2):307-321. https://doi.org/10. 1016/s0016-7037(96)00355-9

Herbert ER, Boon P, Burgin AJ et al (2015) A global perspective on wetland salinization: ecological consequences of a growing threat to freshwater wetlands. Ecosphere 6(10):1-43. https://doi.org/10. 1890/ES14-00534.1

Jiang M, Sheng Y, Liu Q et al (2020) Conversion mechanisms between organic sulfur and inorganic sulfur in surface sediments in coastal rivers. Sci Total Environ 141829. https://doi.org/10.1016/J. SCITOTENV.2020.141829

Jordan TE, Cornwell JC, Boynton WR, Anderson JT (2008) Changes in phosphorus biogeochemistry along an estuarine salinity gradient: the iron conveyer belt. Limnol Oceanogr 53(1):172-184. https:// doi.org/10.4319/LO.2008.53.1.0172

Kraal P, Burton ED, Bush RT (2013) Iron monosulfide accumulation and pyrite formation in eutrophic estuarine sediments. Geochim Cosmochim Acta 122:75-88. https://doi.org/10.1016/j.gca.2013. 08.013

Latour P, Hong WL, Sauer S et al (2018) Dynamic interactions between iron and sulfur cycles from Arctic methane seeps. Biogeosci Discuss:1-48. https://doi.org/10.5194/bg-2018-223

Leng MJ, Lewis JP (2017) C/N ratios and carbon isotope composition of organic matter in estuarine environments. Applications of Paleoenvironmental Techniques in Estuarine Studies:213-237. https://doi.org/10.1007/978-94-024-0990-1-9

Letelier-Gordo CO, Aalto SLH, Suurnäkki S, Pedersen PB (2020) Increased sulfate availability in saline water promotes hydrogen sulfide production in fish organic waste. Aquac Eng 89:102062. https:// doi.org/10.1016/J.AQUAENG.2020.102062

Li H, Liu L, Li M, Zhang X (2013) Effects of pH, temperature, dissolved oxygen, and flow rate on phosphorus release processes at the sediment and water Interface in storm sewer. J Anal Methods Chem 15: 104316. https://doi.org/10.1155/2013/104316

Li J, Lin S, Qin S (2016) Characteristics of sediment bacterial community in response to environmental impacts in a sewage polluted river. J Coast Res 74(sp1):196-206. https://doi.org/10.2112/si74-017.1

Liu X, Fike D, Li A, Dong J et al (2019) Pyrite sulfur isotopes constrained by sedimentation rates: evidence from sediments on the East China Sea inner shelf since the late pleistocene. Chem Geol 505:66-75. https://doi.org/10.1016/j.chemgeo.2018.12.014

Łukawska-Matuszewska K, Graca B, Brocławik O, Zalewska T (2019) The impact of declining oxygen conditions on pyrite accumulation in shelf sediments (Baltic Sea). Biogeochemistry 142(2):209-230. https://doi.org/10.1007/S10533-018-0530-2

Murphy J, Riley JP (1962) A modified single solution method for determination of phosphate in natural waters. Analytical Glumi Acta 27: 31-36. https://doi.org/10.1016/S0003-2670(00)88444-5

Oueslati W, Helali MA, Zaaboub N et al (2018) Sulfide influence on metal behavior in a polluted southern Mediterranean lagoon: implications for management. Environ Sci Pollut Res 25(3):2248-2264. https://doi.org/10.1007/S11356-017-0529-6

Pan F, Guo Z, Cai Y et al (2019) Kinetic exchange of remobilized phosphorus related to phosphorus-ironsulfur biogeochemical coupling in coastal sediment. Water Resour Res 55(12):10494-10517. https:// doi.org/10.1029/2019WR025941

Pandey J, Singh R (2017) Heavy metals in sediments of Ganga River: upand downstream urban influences. Appl Water Sci 7(4):1669-1678. https://doi.org/10.1007/s13201-015-0334-7

Raiswell R, Berner RA (1985) Pyrite formation in euxinic and semieuxinic sediments. Am J Sci 285(8):710-724. https://doi.org/10. 2475/AJS.285.8.710

Ruban V, López-Sánchez JF, Pardo P et al (2001) Harmonized protocol and certified reference material for the determination of extractable contents of phosphorus in freshwater sediments - a synthesis of recent works. J Electroanal Chem 370(2):224-228. https://doi.org/ $10.1007 /$ S002160100753

Sakai S, Nakaya M, Sampei Y et al (2013) Hydrogen sulfide and organic carbon at the sediment-water interface in coastal brackish Lake Nakaumi. SW Japan Environ Earth Sci 68(7):1999-2006. https:// doi.org/10.1007/s12665-012-1887-5

Serban RD, Sipos G, Popescu M et al (2015) Comparative grain-size measurements for validating sampling and pretreatment techniques in terms of solifluction landforms, southern Carpathians, Romania. J Environ Geogr 8(1-2):39-47. https://doi.org/10.1515/jengeo-20150005

Sheng Y, Sun Q, Shi W et al (2015) Geochemistry of reduced inorganic sulfur, reactive iron, and organic carbon in fluvial and marine surface sediment in the Laizhou Bay region, China. Environ Earth Sci 74(2):1151-1160. https://doi.org/10.1007/S12665-015-4101-8

Slomp CP, Mort HP, Jilbert T, Reed DC, Gustafsson BG, Wolthers M (2013) Coupled dynamics of iron and phosphorus in sediments of an oligotrophic coastal basin and the impact of anaerobic oxidation of methane. PLoS One 8(4):e62386. https://doi.org/10.1371/journal. pone. 0062386

Song J, Liu Q, Sheng Y (2019) Distribution and risk assessment of trace metals in riverine surface sediments in gold mining area. Environ Monit Assess 191(3):191. https://doi.org/10.1007/S10661-0197311-9

Souza LR, Knöller K, Ladeira ACQ (2016) Sulfur isotope fractionation and sequential extraction to assess metal contamination on lake and river sediments. J Soils Sediments 16(7):1986-1994. https://doi.org/ 10.1007/S11368-016-1410-9

Sun Q, Sheng Y, Yang J et al (2016) Dynamic characteristics of sulfur, iron and phosphorus in coastal polluted sediments, north China. Environ Pollut 219:588-595. https://doi.org/10.1016/j.envpol. 2016.06.019

Thouvenot-Korppoo M, Lukkari K, Järvelä J et al (2012) Phosphorus release and sediment geochemistry in a low-salinity water bay of the Gulf of Finland. Boreal Environ Res 17(17):237-251. https:// doi.org/10.1117/1.JRS.6.063545

Wu S, Zhao Y, Chen Y et al (2019) Sulfur cycling in freshwater sediments: A cryptic driving force of iron deposition and phosphorus mobilization. Sci Total Environ 657:1294-1303. https://doi.org/10. 1016/j.scitotenv.2018.12.161

Yang S, Tang M, Yim WS et al (2011) Burial of organic carbon in Holocene sediments of the Zhujiang (Pearl River) and Changjiang (Yangtze River) estuaries. Mar Chem 123(1-4):1-10. https://doi. org/10.1016/j.marchem.2010.07.001

Yang Y, Chen Q, Zhang G (2013) Determination of sulfate in coastal salt marsh sediments with high-chloride concentration by ion chromatography: a revised method. Instrum Sci Technol 41(1):37-47. https://doi.org/10.1080/10739149.2012.717330

Yang J, Paytan A, Yang Y et al (2020) Organic carbon and reduced inorganic sulfur accumulation in subtropical saltmarsh sediments along a dynamic coast, Yancheng, China. J Mar Syst 103415. https://doi.org/10.1016/j.jmarsys.2020.103415

Yi L, Gao B, Liu H et al (2020) Characteristics and assessment of toxic metal contamination in surface water and sediments near a uranium 
mining area. Int J Environ Res Public Health 17(2):548. https://doi. org/10.3390/ijerph 17020548

Zhang H, Yu J, Zhou S (2014) Spatial distribution of As, Cr, Pb, Cd, Cu, and $\mathrm{Zn}$ in the water and sediment of a river impacted by gold mining. Mine Water Environ 33(3):206-216. https://doi.org/10.1007/ s10230-013-0254-4

Zhao G, Sheng Y, Jiang M et al (2019) The biogeochemical characteristics of phosphorus in coastal sediments under high salinity and dredging conditions. Chemosphere 215:681-692. https://doi.org/ 10.1016/j.chemosphere.2018.10.015

Zhu MX, Liu J, Yang GP et al (2012) Reactive iron and its buffering capacity towards dissolved sulfide in sediments of Jiaozhou Bay,
China. Mar Environ Res 80:46-55. https://doi.org/10.1016/j. marenvres.2012.06.010

Zhuang W, Gao X (2013) Acid-volatile sulfide and simultaneously extracted metals in surface sediments of the southwestern coastal Laizhou Bay, Bohai Sea: concentrations, spatial distributions and the indication of heavy metal pollution status. Mar Pollut Bull 76(1-2):128-138. https://doi.org/10.1016/j.marpolbul.2013.09.016

Publisher's note Springer Nature remains neutral with regard to jurisdictional claims in published maps and institutional affiliations. 